\title{
The direct solid-solid reaction between coal char and iron-based oxygen carrier and its contribution to solid-fueled chemical looping combustion
}

\author{
Liangyong Chen ${ }^{1}$, Jinhua Bao ${ }^{1}$, Liang Kong ${ }^{1}$, Megan Combs $^{1}$, Heather S Nikolic ${ }^{1}$, Zhen Fan ${ }^{1}$, Kunlei \\ $\mathrm{Liu}^{1,2 *}$
}

1. Center for Applied Energy Research, University of Kentucky, 2540 Research Park Drive, Lexington, KY 405118410, United States;

2. Department of Mechanical Engineering, University of Kentucky, Lexington, KY 40506

*Corresponding author: (+1) 859257 0293;E-mail address: kunlei.liu@uky.edu

\begin{abstract}
Chemical looping combustion (CLC) is an advanced technology developed to achieve highly efficient fuel combustion with in-situ $\mathrm{CO}_{2}$ capture. In this process, metal oxide particles are used as an oxygen carrier (OC) to transport lattice oxygen for fuel combustion. In this process, a stream of $\mathrm{CO}_{2}$ and steam is produced by successful separation of atmospheric $\mathrm{N}_{2}$ and the gaseous product of combustion. In CLC of solid fuel, metal oxide particles are physically mixed and react with solid fuel at high temperature using gasification enhancer, such as steam, or $\mathrm{CO}_{2}$. A full understanding of the reaction mechanism between the OC and solid fuel is vital for OC development and the fuel reactor design. Several reactions may be involved in solid-fueled CLC when an iron-based OC is used, including (1) solid fuel devolatilization /gasification, (2) OC reduction with intermediate syngas, (3) the solid-solid reaction between OC and solid fuel via direct contact, and (4) the homogeneous water-gas shift reaction. The former two reactions have been extensively studied in recent years. This study focuses on the third reaction, the solid-solid reaction, which occurs thermodynamically at typical operational temperatures of CLC. The direct solid-solid reaction between coal char and two iron-based OCs via random particle collision in a fluidization bed regime was investigated and focuses on the reaction kinetics and the carbon conversion at different temperature. The contribution of the solid-solid reaction to the global carbon conversion was estimated for steam-gasified CLC at different temperature. The solid-solid reaction via static contact in a thermal-gravimetric analyzer (TGA) was also tested to evaluate the role of different OCs and to better understand the reaction mechanism between the two solid particles.
\end{abstract}

Key Words: Chemical looping combustion; Solid fuel; Iron-based oxygen carrier; direct solid-solid contact reaction

\section{Introduction}

Chemical looping combustion (CLC) is an advanced emerging technology that captures $\mathrm{CO}_{2}$ from various fossil fuels during power generation. Its overwhelming advantage to the other $\mathrm{CO}_{2}$ capture technologies is the direct separation of $\mathrm{CO}_{2}$ from flue gas during fuel combustion. This process eliminates the need for additional equipment and energy demand for gas separation [1, 2]. In CLC process, two reactors, the air and the fuel reactors are connected in a loop. Fuel is introduced to the fuel reactor (FR) where it is converted to $\mathrm{CO}_{2}$ and $\mathrm{H}_{2} \mathrm{O}$ by the reduction of metal-based oxide (oxygen carrier, OC). Then the reduced $\mathrm{OC}$ is transported to the air reactor (AR) to be regenerated to its full oxidized state using air. Ideally, the gas stream leaving the FR consists of only $\mathrm{CO}_{2}$ and $\mathrm{H}_{2} \mathrm{O}$. This allows high purity $\mathrm{CO}_{2}$ to be compressed and transported for sequestration after water condensation. In principle, the total amount of heat released from the two reactors is the same as normal fuel combustion with air. CLC system has been extensively studied or tested for both gaseous and solid fuels in recent years, and the latest reviews on the development of CLC technologies are reported by J. Adanez and L.S. Fan [3, 4]. 
Recently, solid-fueled CLC has been attracting more attentions due to the extensive availability and low cost of coal [5-10]. Solid fuel can be utilized by two different methods in CLC. One method is the gasification of coal to syngas followed by the introduction of syngas to the CLC system [3]. The other method is in-situ gasification chemical looping combustion (iG-CLC) [11], as shown in Fig. 1. In this process, the two interconnected fluidized bed reactors are generally used as the AR and FR respectively. Solid fuel is introduced directly to the FR and physically mixed with hot metal-based OCs. So the solid fuel gasification and syngas combustion with OC occur simultaneously. The most important advantage of the iG-CLC over syngas-fueled CLC is the elimination of an air separation unit and extra gasifier. So, the layout of iG-CLC significantly decreases the capital and the operation cost [3]. Another major advantage of iG-CLC is the consistently high concentration of gas products $\left(\mathrm{CO}_{2}\right.$ and $\left.\mathrm{H}_{2} \mathrm{O}\right)$ at extremely low concentration of gasification inhibitors $\left(\mathrm{CO}\right.$ and $\left.\mathrm{H}_{2}\right)$ in the FR. This greatly enhances the overall reaction rate, and reduces solid residence time and fuel reactor size needed for CLC. The average coal gasification rate of iG-CLC is 0.5-2 times higher than external gasification [12, 13], depending on the OCs used. Because of these advantages, effort has been made to investigate iG-CLC technologies, mainly focusing on solid fuel conversion, combustion efficiency, OC reduction kinetics, and process and reactor designs [5-15]. Several reactions are involved in the iG-CLC FR: (1) solid fuel conversion to gaseous fuel via devolatilization and gasification, (2) OC reduction by intermediate gaseous fuel, (3) the solid-solid reaction between solid fuel and $\mathrm{OC}$ which could occur via direct contact at high temperature; (4) the homogeneous water-gas shift reaction. Both of the gas-solid reactions (1\&2) are considered to be the two major chemical processes of the FR which dominates the overall reaction of fuel conversion. The watergas shift reaction takes place between the gas products and influences the final gas composition [16].

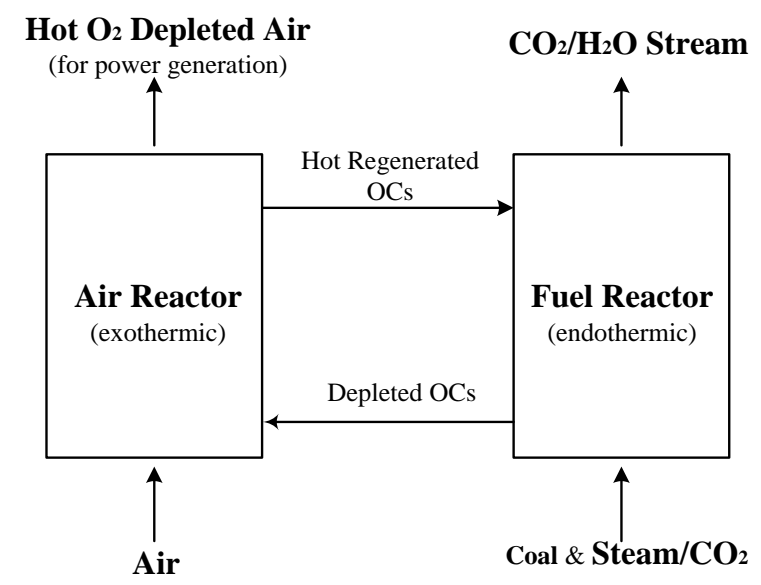

Fig. 1. Chemical-looping combustion for power generation and $\mathrm{CO}_{2}$ capture

At present, the direct reaction between solid fuel and OC particles is still a scientific curiosity. There are two points of interests for this type of reaction which aim to address how solid fuel reacts with metal oxides, and identify its contribution to the overall solid fuel conversion in CLC. Experimental results from several investigations on CLC indicate the existence of a direct solid-solid reaction between char and $\mathrm{Cu}-$, Mn-, Fe- and Ni-based OCs [17-21]. Most of the current research assumes that the solid-solid reaction occurs at an inappreciable rate when the FR is operated at typical temperature of CLC (800-1200 $\left.{ }^{\circ} \mathrm{C}\right)$ [22]. Fundamental research using a Cu-based OC [17] suggests that the solid-solid reaction can be achieved at much lower temperature, below the decomposition temperature of $\mathrm{CuO}$. The authors reported 
that the reaction rate should be considered as long as adequate contact between solid fuel and metal oxide is present. Their data indicate that the carbon induced the $\mathrm{Cu}-\mathrm{O}$ bond breaking to initiate the combustion of carbon at temperatures significantly lower than the decomposition temperature of $\mathrm{CuO}$. The surface melting of $\mathrm{Cu}$ and wetting of carbon contributes to the solid-solid contact necessary for the reaction. Obvious carbon conversion occurs in the range of 0.22 - 1.0 when $\mathrm{Cu}$-based OC and coal char were fluidized by $\mathrm{N}_{2}$ at $900{ }^{\circ} \mathrm{C}$ [18]. Iron-based OCs had been considered one of most suitable candidates for iG-CLC [20]. Our thermodynamic analysis in free energy indicates that the carbon-iron oxide $\left(\mathrm{Fe}_{2} \mathrm{O}_{3}\right)$ reaction initially occurs at a temperature as low as $398{ }^{\circ} \mathrm{C}$. Obviously, the reaction at this temperature is unlikely to proceed at an appreciable rate. On the other hand, the direct reaction between carbon and iron oxide $\left(\mathrm{Fe}_{2} \mathrm{O}_{3}\right)$ has been experimentally observed at $689-715^{\circ} \mathrm{C}$ [17]. However, this temperature region is much lower than the proposed operational temperature $\left(850-1200{ }^{\circ} \mathrm{C}\right)$ where the iron-based materials are used as OCs. However, to date, no experiments have been conducted to neither explore the mechanism of iron-based OC reactions with char nor explain the role or contribution of this reaction in solid fuel conversion.

This study aims to address the research gaps and to provide a better understanding of the solid-solid reaction mechanism. The reactions between two iron-based OCs and thermally treated coal char were investigated both in a TGA apparatus and in a fluidized bed reactor where inert gas was selected as the sweeping gases. Furthermore, the relative reaction rate and the final carbon conversion due to the direct solid-solid reaction were estimated for steam-gasified CLC.

\section{Experimental}

\subsection{Materials}

Two iron-based materials were used for the detection of the solid-solid reaction between coal char and OCs. The first material is a red mud oxygen carrier (RM-OC), which is made from red mud, a solid waste generated in the Bayer process for aluminum production. The RM-OC has been validated as a suitable OC for coal-fueled CLC [23]. The other material is a synthetic oxygen carrier (SYN-OC), which is synthesized from the mixture of 50 wt. $\% \mathrm{Fe}_{2} \mathrm{O}_{3}$ and 50 wt. $\% \mathrm{Al}_{2} \mathrm{O}_{3}$. Hematite $\left(\mathrm{Fe}_{2} \mathrm{O}_{3}\right)$ and alumina $(\gamma$ $\mathrm{Al}_{2} \mathrm{O}_{3}$ ) used for $\mathrm{SYN}-\mathrm{OC}$ production were purchased from Alfa Aesar and Inframat Advanced Materials LLC. Their average particle size is $5 \mu \mathrm{m}$ and $45 \mu \mathrm{m}$, respectively. The RM- and SYN- OCs used in this study were made by lab-scale freeze-granulation. 1,000 g of dry powder $\left(50 \% \mathrm{Fe}_{2} \mathrm{O}_{3}\right.$ and $50 \% \gamma-\mathrm{Al}_{2} \mathrm{O}_{3}$ for the SYN-OC, or $100 \%$ red mud with $\mathrm{d}_{50}<20 \mu \mathrm{m}$ for the RM-OC), 1,000 g deionized water, $100 \mathrm{~g}$ polyvinyl alcohol (Sigma-Aldrich, St. Louis, MO), and $10 \mathrm{~g}$ dispersant (DISPEX A40 (V), Ciba, Switzerland) were mixed and made into slurries. The mixture was stirred via a wet ball mill for 24 hours to obtain homogeneity. Frozen spherical particles were generated as the slurry was sprayed through a nozzle into liquid nitrogen, and then subsequently were dried in a vacuum freeze dryer. The dry particles were baked for 6 hours at $1,400{ }^{\circ} \mathrm{C}$ for the SYN-OC and at $1,150^{\circ} \mathrm{C}$ for the RM-OC. Then the calcinated materials were then sieved through stainless steel screens, and 125-350 $\mu \mathrm{m}$ particles were collected for experimentation. The chemical composition of the RM-OC was identified by XRF and includes $\mathrm{Fe}_{2} \mathrm{O}_{3}$, $\mathrm{SiO}_{2}, \mathrm{Al}_{2} \mathrm{O}_{3}, \mathrm{TiO}_{2}, \mathrm{CaO}$, and a small amount of alkaline metal $\left(\mathrm{Na}_{2} \mathrm{O}\right)$. Table 1 summarizes the chemical composition and physical properties for the two iron-based OCs, and Fig. 2 shows the SEM images of the fresh OC particles at different magnifications.

Coal char prepared from PRB coal (Power River Basin coal, USA) was used as solid fuel in order to mitigate the complexity of coal volatility and moisture in the initial reaction. In coal char preparation, the 
raw coal with a particle size of $90-500 \mu \mathrm{m}$ was heated to $800{ }^{\circ} \mathrm{C}$ in a fixed bed reactor at a rate of 20 ${ }^{\circ} \mathrm{C} / \mathrm{min}$ and then held at $800{ }^{\circ} \mathrm{C}$ for $60 \mathrm{~min}$. During pyrolysis, $\mathrm{N}_{2}$ gas flowed through the fixed bed at a rate of $3.0 \mathrm{~L} / \mathrm{min}$. The coal char products were crushed and sieved, and the particles in the range of 180-350 $\mu \mathrm{m}$ were used for experimentation. The proximate and ultimate analyses of the coal char are presented in Table 2.
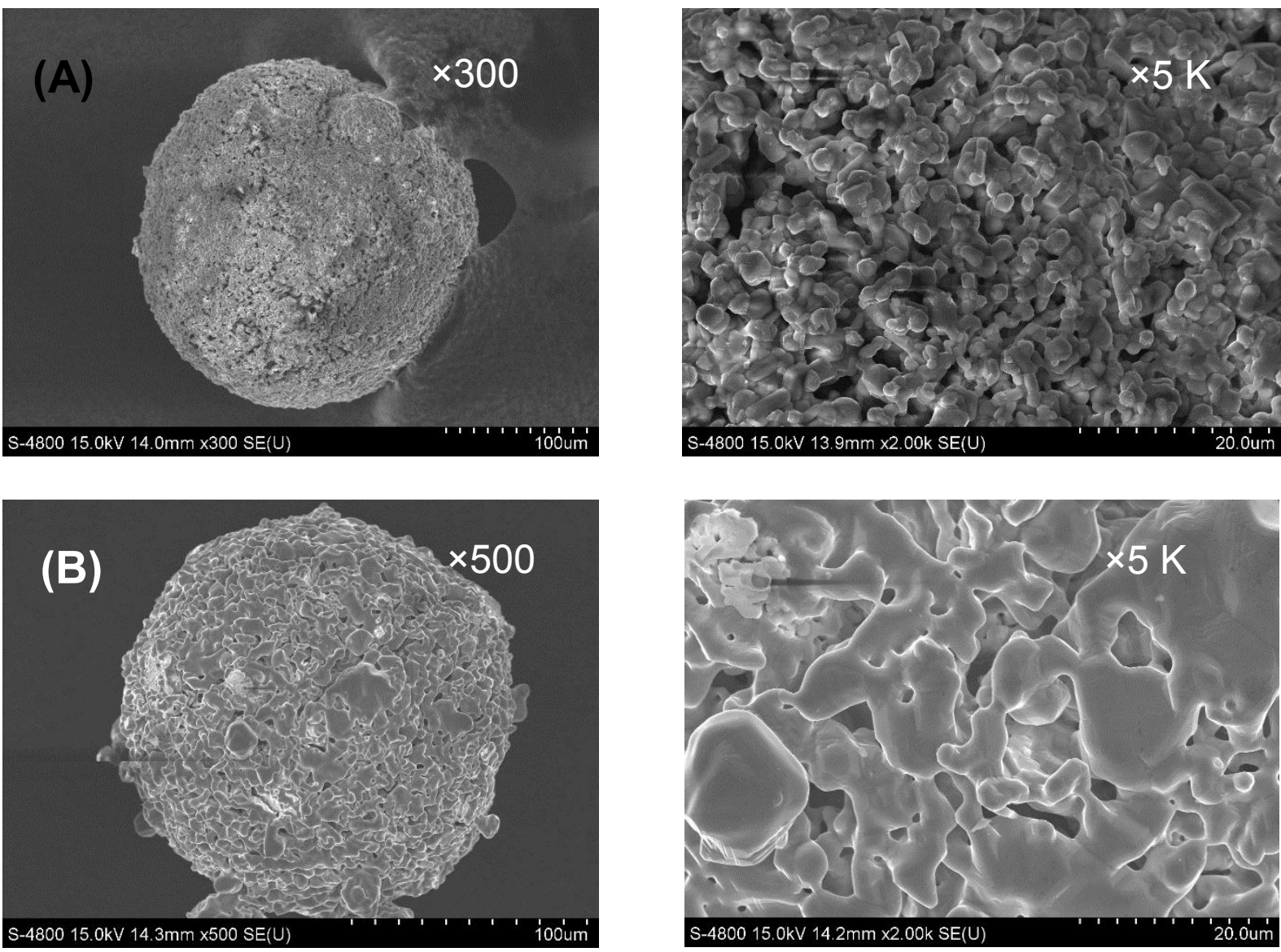

Fig. 2. SEM images of OC particles (A) RM-OC and (B) SYN-OC

Table 1 Chemical composition and physical properties of iron-based OCs (wt \%)

\begin{tabular}{|c|c|c|c|}
\hline Composite & & RM-OC & SYN-OC \\
\hline $\mathrm{Fe}_{2} \mathrm{O}_{3}$ & & 51.56 & 50 \\
\hline $\mathrm{SiO}_{2}$ & & 9.98 & - \\
\hline $\mathrm{Al}_{2} \mathrm{O}_{3}$ & & 18.18 & 50 \\
\hline $\mathrm{TiO}_{2}$ & & 6.47 & - \\
\hline $\mathrm{CaO}$ & & 7.77 & - \\
\hline $\mathrm{MgO}$ & & 0.51 & - \\
\hline $\mathrm{Na}_{2} \mathrm{O}$ & & 1.85 & - \\
\hline Balance & & 3.70 & - \\
\hline Effective Density & $\mathrm{g} / \mathrm{cm}^{3}$ & 3,734 & 4,076 \\
\hline BET Surface Area & $\mathrm{m}^{2} / \mathrm{g}$ & 0.244 & 0.336 \\
\hline Softening Temperature & ${ }^{\circ} \mathrm{C}$ & 1,360 & $>1,500$ \\
\hline
\end{tabular}


Table 2 Proximate and Ultimate Analyses of PRB Coal Char

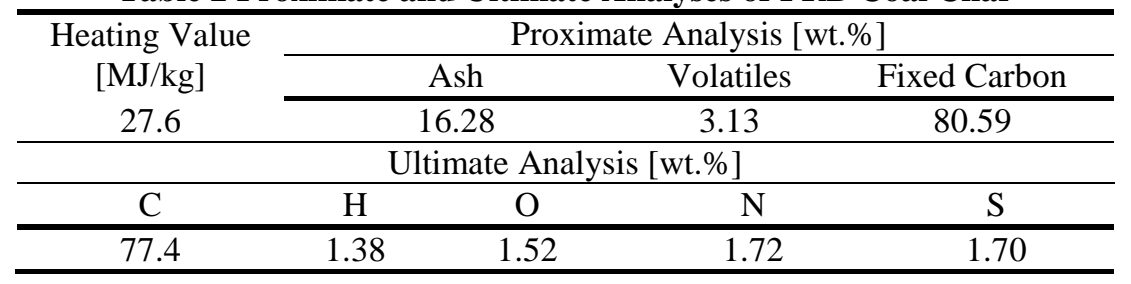

\subsection{Experiment setup and test procedure}

A fluidized bed reactor (FBR) was used to test the solid-solid reaction with dynamic contact between char and OCs. Its schematic diagram is shown in Fig. 3. The body of reactor was fabricated from 310 stainless steel pipe with an inner diameter (ID) of $43 \mathrm{~mm}$ and a height of $750 \mathrm{~mm}$. A metal porous media plate was used as a gas distributor to ensure uniform fluidization, which was placed $250 \mathrm{~mm}$ above the bottom of the reactor. An electric oven with a rated power of $3 \mathrm{~kW}$ surrounded the FBR to maintain a uniform distribution of the reaction temperature during the experiment. The bed temperature was measured by a K-type thermocouple inserted from the top of the reactor with its tip $50 \mathrm{~mm}$ above the gas distributor. The total pressure drop across the gas distributor and bed materials is measured by a pressure transducer. The flow rates of the feeding gas are controlled by mass flow controllers (MFC). A syringe pump supplied the desired amount of deionized water to a steam generator where the mixture of steam and feeding gas are pre-heated to $600{ }^{\circ} \mathrm{C}$ before entering the reactor. The feeding of char is accomplished using a stainless steel tube inserted from the top of the reactor. The end of tube was $50 \mathrm{~mm}$ above the gas distributor in order to feed the coal char into the center of the hot bed materials. The FBR exit gas passed through a cyclone, high temperature filter, cooler, and moisture trap in sequence to remove fine particles and water condensate. The concentration profiles of the dry exit gas were measured using a Rosemount multi-gas analyzer (X-stream serial) which measures different gaseous components, including $\mathrm{O}_{2}, \mathrm{CH}_{4}, \mathrm{CO}, \mathrm{CO}_{2}$, and $\mathrm{H}_{2}$. Gas concentration, pressure drop, temperature, and flow rate were recorded using a computerized data acquisition system.

Three series of tests were conducted in FBR, including the solid-solid reaction under dynamic contact conditions, coal char-fueled CLC and coal char deep pyrolysis. The solid-solid reaction experiments were conducted at three different temperatures, i.e. $850{ }^{\circ} \mathrm{C}, 950{ }^{\circ} \mathrm{C}$, and $1,050{ }^{\circ} \mathrm{C}$, respectively. The OCs (RMOC or SYN-OC in fully oxidized form) were initially loaded in the FBR at $215.0 \mathrm{~g}$. The static bed heights was $115 \mathrm{~mm}$ for the RM-OC and $10.5 \mathrm{~mm}$ for the SYN-OC. Then the bed materials were heated to the desired temperature in high purity $\mathrm{N}_{2}$ steam $(99.999 \%)$ at a flow rate of $5.0 \mathrm{~L} / \mathrm{min}$ (standard conditions). When the bed temperature stabilized, $2.0 \mathrm{~g}$ PRB coal char was quickly introduced to the reactor at the start of experiment. The solid-solid reaction was monitored by measuring the concentration of carbon containing gases in sweep gas. At the end of the reaction, a combustion step was performed to burn out the unreacted char and to regenerate the OCs using $3.0 \mathrm{~L} / \mathrm{min}$ air flow. This allows for an accurate calculation of oxygen and carbon mass balance for each experiment. Both the OC and char particles are operated at slow bubbling fluidization regime in reduction step. The superficial velocity in the reactor, $U_{\mathrm{o}}$ is about 3.0-4.5 times of minimum fluidizing velocity ( $\left.U_{\mathrm{mf}}\right)$ of the OC particles, and 10- 13 times of $U_{\mathrm{mf}}$ of coal char particles. Even at highest temperature $\left(1,050{ }^{\circ} \mathrm{C}\right), U_{\mathrm{o}}$ is much lower than the terminal velocity, $U_{\mathrm{t}}$ of coal char particles, ensuring the carryover of char particles from the bed materials is quite low. 
In order to determine the contribution of the dynamic solid-solid contact reaction, CLC experiments were operated at similar conditions to obtain the overall kinetics of coal char conversion. But in the CLC experiments, the fluidizing gases were replaced by a mixing gas of $50 \%$ steam and $50 \% \mathrm{~N}_{2}(1.5 \mathrm{~g}$ water and $2.0 \mathrm{~L} / \mathrm{min}_{2}$ ). Here the steam acts as enhancer to gasify the coal char into syngas for the reduction of OCs.

Coal char deep pyrolysis was tested in order to set up a baseline for the duration of pyrolysis and the amount of volatile released in the FBR. The devolatilization of coal char is temperature dependent. Accordingly, the deep pyrolysis experiments were performance at $850{ }^{\circ} \mathrm{C}, 950{ }^{\circ} \mathrm{C}$, and $1,050{ }^{\circ} \mathrm{C}$, respectively, and followed the same procedure as the dynamic solid-solid reactions. $215.0 \mathrm{~g}$ quartz sand, $0.5 \mathrm{~g}$ PRB coal char and $5.0 \mathrm{~L} / \mathrm{min}$ sweeping gas $\left(\mathrm{N}_{2}\right)$ were applied for each test. The quartz sand has a similar particle size and density to the SYN-OC. Approximately $100 \mathrm{~s}$ after the completion of deep pyrolysis, a $3.0 \mathrm{~L} / \mathrm{min}$ air stream was applied to remove any residual carbon.

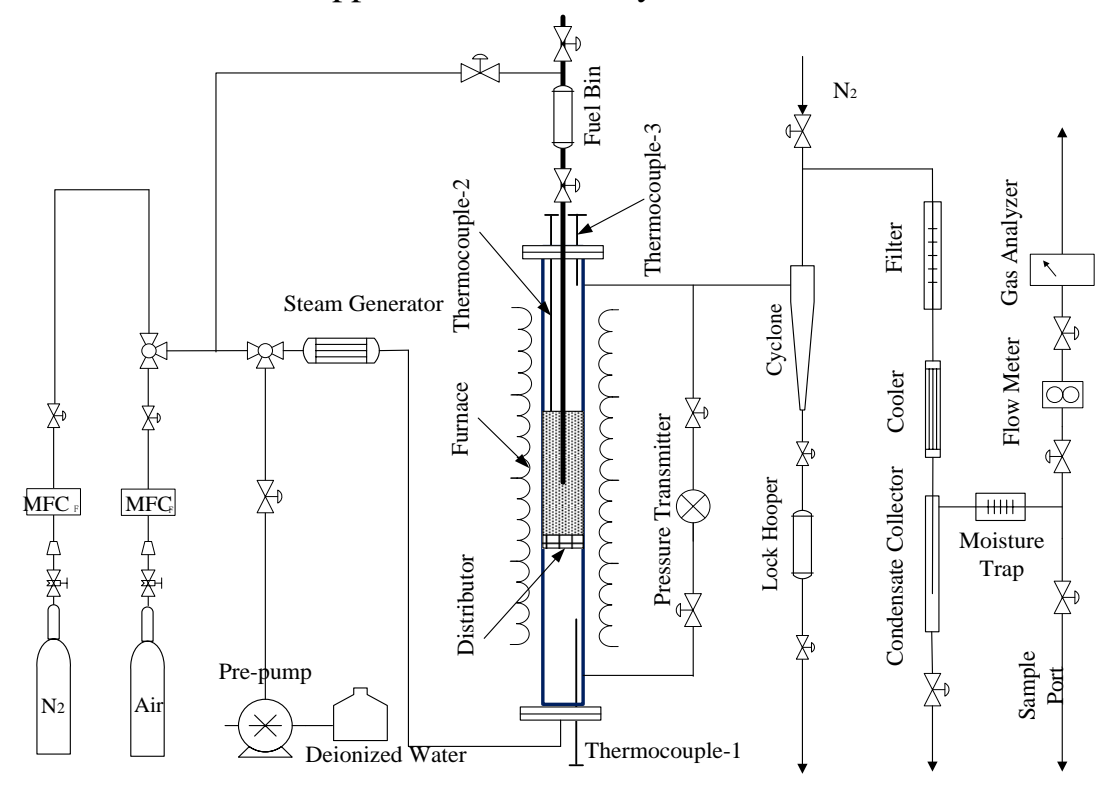

Fig. 3. Schematic layout of fluidized bed reactor

The static contact solid-solid reaction experiments between coal char and OCs (or quartz sand) would provide the understanding of the role of OCs and the reaction mechanism between the solid particles. These experiments were conducted in a thermo-gravimetric analyzer (TGA, Netzsch STA 449 F3 Jupiter) equipped with a mass spectroscopy (Aeolos QMS403) to measure of gases constituents in the evolved stream. With the exception of the two OCs, inert sand (acid washed, 125-350 $\mu \mathrm{m}$ ) was used for static contact solid-solid reaction where it was assumed no lattice oxygen is transferred for solid fuel conversion. The well premixed PRB coal char with OCs (or quartz sand) at a weight ratio of 1: 20 (mg: $\mathrm{mg}$ ) was heated to $950{ }^{\circ} \mathrm{C}$ at a rate of $10{ }^{\circ} \mathrm{C} / \mathrm{min}$. At the same time, the furnace was purged with a $200 \mathrm{ml} / \mathrm{min}$ argon gas stream, and the weight change was measured to determine the carbon conversion. When the weight profile leveled off, the solid sample was cooled and then subjected to SEM-EDX analysis. 


\section{Results and discussion}

\subsection{Dynamic contact solid-solid reaction in fluidized bed reactor}

Fig. 4 (a) shows the gas concentration profiles from the dynamic contact solid-solid reaction tested at 950 ${ }^{\circ} \mathrm{C}$ with the solid pair of RM-OC and PRB char. The results show an appreciable amount of coal char oxidation in the high purity $\mathrm{N}_{2}$ stream, and only the presence of $\mathrm{CO}_{2}$ gas in the exhaust gas. The other combustible gases, such as $\mathrm{CO}, \mathrm{H}_{2}$ or $\mathrm{CH}_{4}$ were not detected. As seen in Fig. 4 (a), very stable reaction takes place between 40-2,250 seconds, corresponding to an average $\mathrm{CO}_{2}$ concentration of $0.54 \%$. Here, the first 40 seconds were excluded because of the impact of the minor residual volatile, as will be illustrated by the coal char deep pyrolysis experiments. After 2,250 s, a slow decrease in $\mathrm{CO}_{2}$ concentration was observed until 4,500 s, indicating continuous decay of char conversion. Fig. 4 (b) shows the resulting gas concentration profile from the similar experiment using solid pairs of SYN-OCs and PRB coal char. A very similar observation was seen, but a lower $\mathrm{CO}_{2}$ concentration was generated for the use of SYN-OCs.

Due to the absence of gaseous oxygen introduced to the FBR during $\mathrm{N}_{2}$ gas feed, the lattice oxygen in Febased OC particles was the sole source of available oxygen for coal char combustion during the dynamic contact solid-solid reaction. During the air combustion steps shown in Fig. 4 (a) and (b), there is OC oxidation occurring prior to residual carbon combustion, as indicated by a long period of time (4,500 $4,700 \mathrm{~s}$ and 5,545 - 5,695 s) of $\mathrm{O}_{2} / \mathrm{CO}_{2}$ free gas profile after the introduction of air. Here the uptake of gaseous oxygen by the OCs strongly suggests that the full oxidized OCs were oxygen donators for coal char conversion during the dynamic contact solid-solid reaction. Furthermore, a subtle oxygen closure was achieved for each of experiments, showing the amount of oxygen consumed via the direct contact solid-solid reaction is equivalent to the uptake of gaseous oxygen by the OCs during the air combustion step (See S-Table 1). For example, the oxygen uptake for OC regeneration is $0.157 \mathrm{~mol}$, while the calculated value of lattice oxygen consumption by coal char is $0.165 \mathrm{~mol}$, suggesting a good oxygen closure of $95.2 \%$.
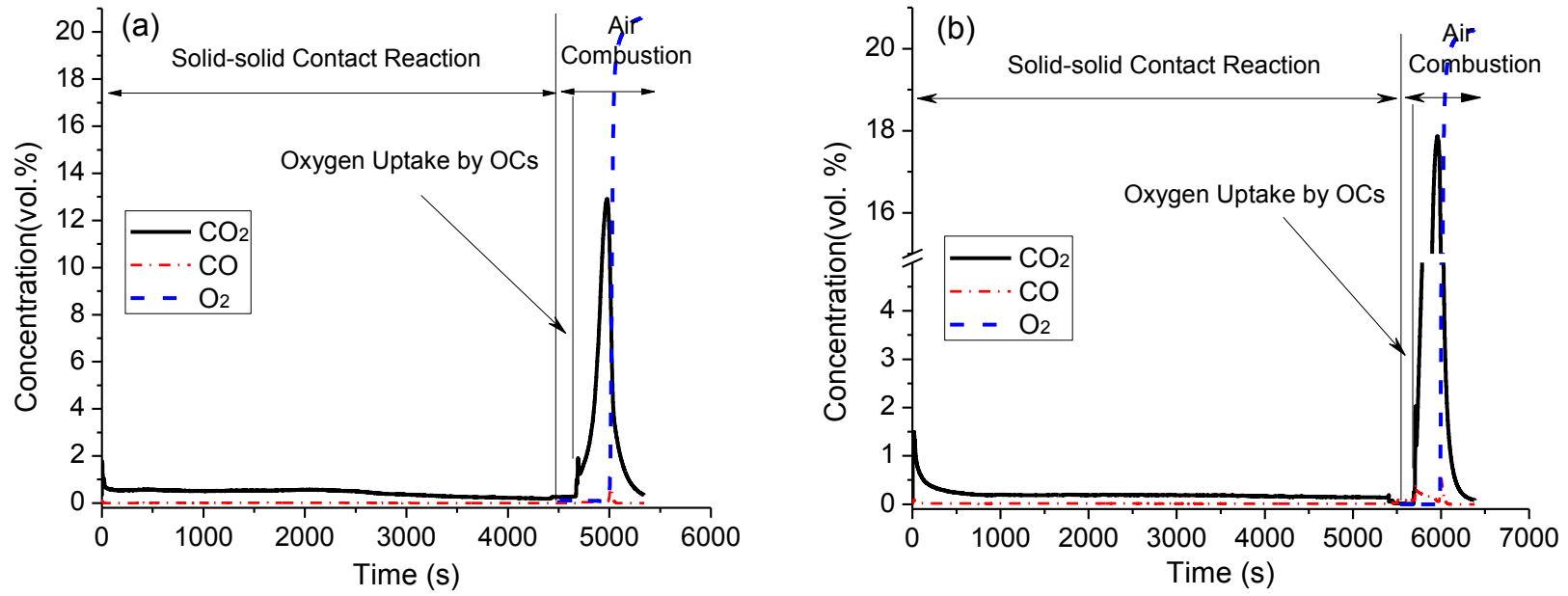

Fig. 4 Gas concentration profiles during the dynamic contact solid-solid reaction between (a) coal char and RM-OC, and (b) coal char and SYN-OC $\left(\mathrm{T}=950^{\circ} \mathrm{C}\right.$; Fuel: $2.0 \mathrm{~g}$ PRB char; Bed materials: $215.0 \mathrm{~g}$ Fe-based OCs; Fluidizing gas: $5.0 \mathrm{~L} / \mathrm{min}_{2}$ for the reduction period and $3.0 \mathrm{~L} / \mathrm{min}$ air for residual carbon combustion and $\mathrm{OC}$ regeneration) 
When the experiment is operated at high temperature, the release of gaseous oxygen from the transition of iron oxides, also known as oxygen uncoupling effects, could initiate the "solid-solid reaction". With the oxygen uncoupling effects, the char reacts with gaseous oxygen rather than the solid OC particles [24]. The theoretical temperature for thermal transition of pure $\mathrm{Fe}_{2} \mathrm{O}_{3}$ to $\mathrm{Fe}_{3} \mathrm{O}_{4}$ is $1,566^{\circ} \mathrm{C}$ [17], which is much higher than the operational temperature used in this study. However, the two iron-based OCs are a mixture and possess a complex phase structure. This complex structure maybe lowers the transition temperature to release gaseous oxygen. To validate oxygen uncoupling effects, the RM-OC and SYN-OC were heated up to $1,050^{\circ} \mathrm{C}$ in an inert gas stream (without the use of coal char) using the fluidized bed reactor. The results showed the absence of oxygen in the exit gas. This observation excludes the possibility of oxygen uncoupling effects during the dynamic contact solid-solid reaction experiments.

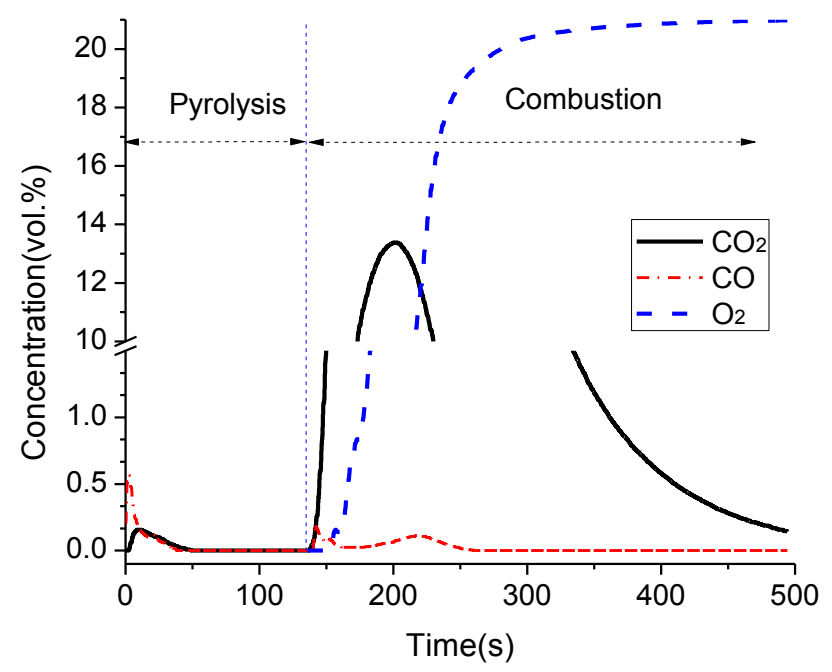

Fig. 5 The flue gas concentration during deep pyrolysis of PRB char (PRB char $0.5 \mathrm{~g}$; Temperature: $950^{\circ} \mathrm{C}$; Bed material: $215.0 \mathrm{~g}$ quartz sand; air for residual carbon combustion: $3.0 \mathrm{~L} / \mathrm{min}$ )

Residual volatile release from coal char could impact the solid-solid reaction. Minor volatiles may initiate the reaction between coal char and $\mathrm{OC}$, and subsequent the combustion products $\left(\mathrm{CO}_{2}\right)$ induce an in-situ gasification of coal char continuously. To check this reaction pathway, deep pyrolysis of coal char with inert sand was performed at different temperature $\left(950{ }^{\circ} \mathrm{C}\right.$ and $\left.1050^{\circ} \mathrm{C}\right)$. Although the amount of residual volatiles released from coal char varied with operational temperatures, the equivalent fuel conversion from deep pyrolysis was much less than from the dynamic contact solid-solid reaction. Using coal char deep pyrolysis at $950^{\circ} \mathrm{C}$ as an example (shown in Fig. 5, the result for $1,050{ }^{\circ} \mathrm{C}$ can be find in S-Fig. 1), the equivalent fuel char conversions due to exposure to higher temperature was only $1.15 \%$, as compared with $58 \%$ for the fuel char conversion of the dynamic contact solid-solid reaction. Furthermore, the deep pyrolysis of coal char was confined to the first 30-40 s due to fast kinetics. The short duration of deep pyrolysis is practically negligible as compared to the 4,500 s duration of the solid-solid reaction, as shown in Fig. 4. Alternatively, the nonexistence of $\mathrm{CO}$ in exhaust gas of the dynamic contact solid-solid reaction can also exclude the possibility of minor volatiles induced $\mathrm{CO}_{2}$ gasification. $\mathrm{CO}_{2}$ gasification of coal char would lead to the formation of the intermediate gas, $\mathrm{CO}$, which would become a driving force for the continuous reduction of the OC particles and thus to produce $\mathrm{CO}_{2}$ gas $[13,18]$.

The above experiments and analysis indicates that the intermediate gases (including gaseous oxygen, volatiles, and gasification agent) are not necessary for the reaction between coal char and iron-based OCs. 
The two different particles could directly react with each other at an appreciable rate via the solid-solid contact under typical operational temperatures of CLC.

\subsection{Effect of temperature on dynamic contact solid-solid reaction}

Fig. 6 (a) shows the carbon conversion of the dynamic contact solid-solid reaction at different temperature for two iron-based OCs. The carbon conversion, $x_{\mathrm{c}}$ was obtained from the total carbon emitted into gaseous species at time of $t$ :

$$
x_{c}=m_{c}(t) / m_{\text {tot }}
$$

Here $m_{t o t}$ is the mass of carbon introduced to the FBR in the form of coal char at the beginning of the test, $m_{c}(t)$ is the mass of carbon in the fuel char that is converted to the gas phase at time of $t$. Fig. 6 (b) shows the instantaneous rate of carbon conversion $\left(r_{\mathrm{c}}\right)$ as function of $x_{c}$ for the same tests in Fig. 6 (a). For comparison, $x_{c}$ and $r_{c}$ obtained from CLC experiment at $950{ }^{\circ} \mathrm{C}$ using $50 \%$ steam and the RM-OC are presented in Fig. 6 (a) and (b). In these plots, $r_{c}$ is calculated in the normalized carbon conversion with respect to the amount of residual carbon [13]:

$$
r_{c}=\frac{d x_{c} / d t}{1-x_{c}}
$$

As can be seen, when the temperature is below $850{ }^{\circ} \mathrm{C}$, the solid-solid reactions at dynamic contact conditions are not favorable for either OC. The RM-OC exhibited a higher ability to oxidize coal char than the SYN-OC at $950^{\circ} \mathrm{C}$ and $1,050^{\circ} \mathrm{C}$. The high temperature conditions benefit the reaction to proceed at higher fuel conversion. It is unprecedented that the rapid solid-solid reactions at $1,050{ }^{\circ} \mathrm{C}$ proceed until $30 \mathrm{~min}$ for the RM-OC and $27 \mathrm{~min}$ for the SYN-OC, and result in final carbon conversions of more than $85 \%$ and $64 \%$, respectively. Even at $950{ }^{\circ} \mathrm{C}, 58 \%$ of the final carbon conversion was achieved using the RM-OC, and $40 \%$ using the SYN-OC. No apparent agglomerates were observed when the OC particles were extracted from the FBR after the experiments. It will be shown that the carbon conversions obtained from the FRB were different from that obtained from TGA (static solid-solid contact reaction), with the former showing a higher degree of carbon conversion. This may be attributed to different solid-solid contact in these tests. However, we can conclude that the direct solid-solid contact reaction between ironbased OCs and coal char particles would not be negligible in the CLC process of high temperature ( $\geq 950$ $\left.{ }^{\circ} \mathrm{C}\right)$.

Fig. 6 (b) shows that the operational temperature is a major factor affecting the reaction kinetics. When the operational temperature increase from $950{ }^{\circ} \mathrm{C}$ to $1,050{ }^{\circ} \mathrm{C}$, the average instantaneous carbon conversion rate due to the dynamic contact solid-solid reaction (under steady reaction conditions) improves by a factor of 7.0 for the RM-OC and 9.2 for the SYN-OC. The fuel char conversion behavior is significantly different between the CLC and the dynamic solid-solid contact reaction. In Fig. 6 (b), the $r_{c}$ of CLC gradually increases with $x_{c}$ over the whole reaction, while the $r_{c}$ of the dynamic solid-solid contact reaction shows significant decrease when approaching the final conversion of fuel char. This indicates that the importance of the solid-solid contact reaction gradually diminishes as the fuel char conversion proceeds. The formation of ash shell covering the residual carbon would cause a decrease in the probability of direct contact between OCs and carbon surface of the residual char and decrease the rate of the dynamic solid-solid contact reaction. 

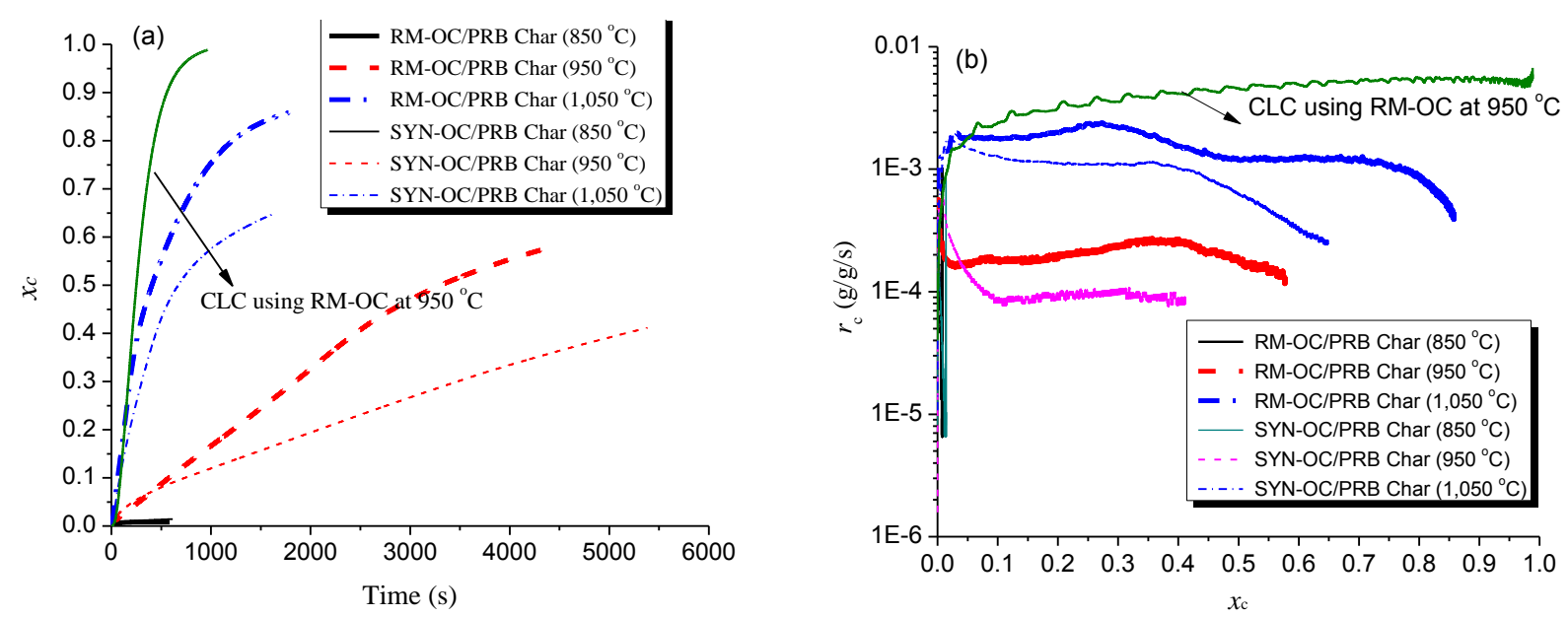

Fig. 6 The effect of temperature on coal char conversion in the dynamic contact solid-solid reaction using the RM-OC and the SYN-OC as bed materials: (a) $x_{\mathrm{c}}$ vs. time, (b) $r_{\mathrm{c}}$ vs. $x_{\mathrm{c}}$ (Fuel: $2.0 \mathrm{~g}$ PRB coal char; Mass of OC: $215.0 \mathrm{~g}$; fluidizing gas: $5.0 \mathrm{~L} / \mathrm{min}_{2}$ gas)

\subsection{Contribution of solid-solid contact reaction}

The high final conversion of fuel char obtained in the dynamic contact solid-solid reaction at high temperature does not imply the same consumption of fuel char via the dynamic contact solid-solid reaction could occur in an actual CLC process. It is of interest to better understand the practical importance and contribution of this reaction to the overall fuel char conversion in CLC. The relative reaction rate at a given carbon conversion, as defined by Equation (3), is used to describe the role of the solid-solid contact reaction in CLC:

$$
a=r_{c, s-s} / r_{c, C L C}
$$

Where $a, r_{c, s-s}$ and $r_{c, C L C}$ are the relative reaction rate, instantaneous rate of carbon conversion due to the dynamic contact solid-solid reaction, and the overall carbon conversion rate in the CLC process, respectively. Eq. (3) assumes that the in-situ gasification (a fast reaction) and dynamic contact solid-solid reaction (a slow reaction) accounts for the total coal char conversion of CLC, and that both are a monotonic function of $x_{\mathrm{c}}$. Therefore, $r_{c, s-\mathrm{s}}$ and $r_{c, C L C}$ can be separately determined from the dynamic solid-solid contact reaction and CLC operated under the similar conditions.

Fig. 7 shows the values of $a$ as a function of $x_{c}$ for the RM-OC and the SYN-OC. At the same operational temperature, the RM-OC exhibits a higher relative reaction rate during the stable reaction period as compared to the SYN-OC. Both OCs show the increasing importance of the solid-solid contact reaction as operational temperature increases from $950{ }^{\circ} \mathrm{C}$ to $1,050{ }^{\circ} \mathrm{C}$. The result of the $850{ }^{\circ} \mathrm{C}$ experiment is not shown due to an extremely low carbon conversion. The calculated value of $a$ is approximately 1.0 at the beginning of the experiments. However, this value does not mean the solid-solid contact reaction in the initial reaction accounts for all carbon conversion. A significant error is introduced at the initial reaction period due to the flash pyrolysis of the coal char. However, it is likely that the solidsolid contact reaction occurring on the superficial surface of the coal char and OCs is fast due to the absence of ash shell between the contact surfaces. 
In order to estimate the total carbon conversion due to the dynamic contact solid-solid reaction in CLC, a coefficient, $A_{\mathrm{c}}$ is defined

$$
A_{c}=\int_{0}^{1} \alpha d x_{\mathrm{c}}=\int_{0}^{X_{c, C L C}} \frac{r_{c, s-\mathrm{s}}}{r_{c, C L C}} d x_{\mathrm{c}} \approx \sum_{0}^{n} \frac{r_{c, s-\mathrm{s}}\left(x_{c, i}\right)}{r_{c, C L C}\left(x_{c, i}\right)} \Delta x_{c, i}=\frac{X_{c, s-s}}{X_{c, C L C}}
$$

Where, $r_{c, s-\mathrm{s}}\left(x_{c, i}\right)$ and $r_{c, C L C}\left(x_{c, i}\right)$ are the discrete values of $r_{c, s-\mathrm{s}}$ and $r_{c, C L C}$ at $x_{c, i}$ respectively; $\Delta x_{c, i}$ is the $i_{t h}$ increment of carbon conversion; $X_{c, s-s}$ and $X_{c, C L C}$ are the final carbon conversion due to the dynamic contact solid-solid reaction and the overall carbon conversion in CLC, respectively. Once the values of $r_{c, s-s}\left(x_{c, i}\right), r_{c, C L C}\left(x_{c, i}\right)$ and $X_{c, C L C}$ are obtained from the dynamic contact solid-solid reaction and CLC tests, the value of $X_{c, s-s}$ can be calculated from Eq.(4). Table 3 summarizes the values of $X_{c, C L C}$ and $X_{c, s-s}$ together with the final carbon conversion of the dynamic solid-solid contact reaction test $\left(X_{c, s-s}^{\prime}\right)$. The dynamic solid-solid contact reaction at a temperature $\geq 950{ }^{\circ} \mathrm{C}$ could lead to extremely high final carbon conversion $\left(X_{c, s-s}^{\prime}\right)$ in absence of in-situ gasification present (i.e. the dynamic solidsolid contact reaction test using inert gas for fluidization can be considered a CLC process with an in-situ gasification rate of zero). However, the scenario are significantly different for the actual CLC process, where the value of $X_{c, s-s}$ is greatly reduced because the in-situ gasification of coal char by the gasification agent (steam) is a stronger competitive parallel reaction. It is worth noting that the impact of the small amount of volatiles at the initial reaction stage is not deducted in the calculation. Thus the values of $X_{c, s-s}$ in Table 3 are slightly overestimated.

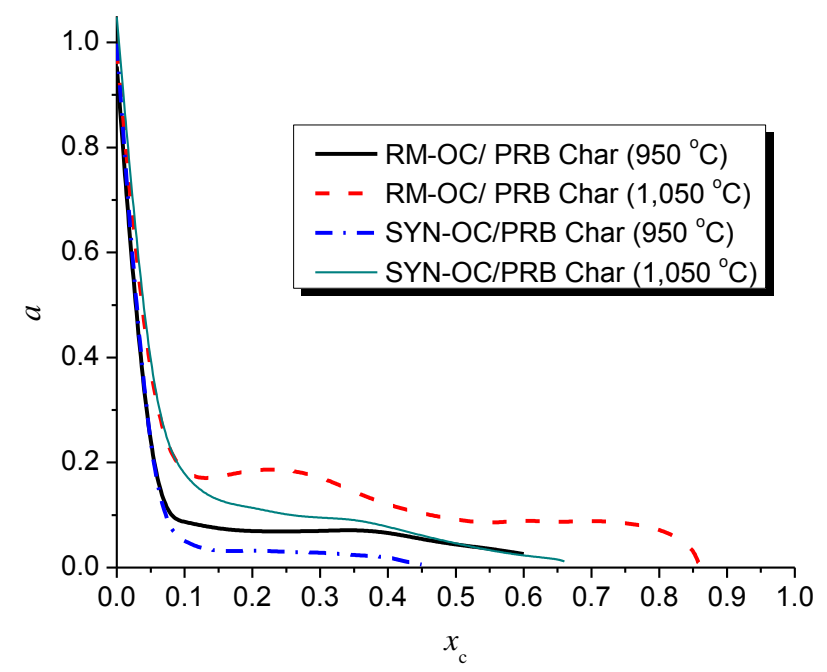

Fig. 7 The relative reaction rates due to the dynamic contact solid-solid reaction between coal char and different OCs in steam-gasified CLC (Bed materials: 215.0 g OC; Fuel: 2.0 g PRB Char; Fluidizing gas: 5.0 $\mathrm{L} / \mathrm{min} \mathrm{N}_{2}$ gas) 
Table 3 Carbon conversion due to solid-solid contact reaction (\%)

\begin{tabular}{|c|c|c|c|c|c|c|}
\hline \multirow{2}{*}{$\begin{array}{c}\text { Temperature } \\
\quad\left({ }^{\circ} \mathrm{C}\right)\end{array}$} & \multicolumn{3}{|c|}{ RM-OC } & \multicolumn{3}{|c|}{ SYN-OC } \\
\hline & $X_{c, C L C}$ & $X_{c, s-s}$ & $X_{c, s-s}^{\prime}$ & $X_{c, C L C}$ & $X_{c, s-s}$ & $X_{c, s-s}^{\prime}$ \\
\hline 1,050 & 99.5 & 13.8 & 85 & 99.3 & 8.7 & 64 \\
\hline 950 & 98.8 & 5.9 & 58 & 99.0 & 4.1 & 40 \\
\hline 850 & 87.4 & - & 1.0 & 89.7 & - & 1.4 \\
\hline
\end{tabular}

\subsection{Static contact solid-solid reaction}

The motivation for conducting static contact solid-solid reaction experiments is to better understand the reaction without particle attrition, and to prepare coal char samples for direct observation of the surface change after the reaction. Furthermore, TGA tests are likely to provide information regarding the role of different OC during the solid-solid reaction. Additionally, the change of gas density during heating up may cause systematic error in sample weight. Blank tests were performed for different OCs (RM-OC, SYN-OC and inert sand) for correction. $420.0 \mathrm{mg}$ sample was used for each blank test and the same procedure as the static contact solid-solid reaction was followed. All weight loss profiles were corrected by differentiating TGA data from the static contact solid-solid reaction and corresponding blank test, as plotted in Fig. 8. The weight loss observed for the solid pair of inert sand/PRB char would be negligible $(0.121 \%)$. This weight loss is attributed to the trivial pyrolysis of coal char. The final weight loss for the solid pair of SYN-OC/PRB char and RM-OC/PRB char were 5.45\% and 8.64\%, respectively. An appreciable amount of $\mathrm{CO}_{2}$ gas was measured by mass spectroscopy (MS) during these experiments. Assuming the weight loss is a consequence of $\mathrm{CO}_{2}$ release (i.e. two moles of oxygen consumed by each mole of carbon), the corresponding carbon conversion of fuel char $31.2 \%$ and $49.4 \%$, respectively. This is a significant conversion, much more than by the release of residual volatile. This conversion provides evidence of the occurrence of the direct solid-solid reaction between coal char and these iron-based OCs.

There are significant differences in the weight loss profiles and the final fuel conversion due to the use of different OCs. Observable weight loss began at $\sim 780{ }^{\circ} \mathrm{C}$ for the SYN-OC and $650{ }^{\circ} \mathrm{C}$ for the RM-OC. Because residual volatile of coal char are not released at these temperatures, which are lower than the coal char pretreatment temperature $\left(800{ }^{\circ} \mathrm{C}\right)$, the initial direct solid-solid reaction between coal char and the OCs should account for observable weight loss. When the temperature is above $900{ }^{\circ} \mathrm{C}$, the rate of the direct solid-solid reaction for the solid pair of SYN-OC/PRB char and RM-OC/PRB char increases rapidly, but behaves differently. This is due to different availability of lattice oxygen at the static contact boundary between coal char and various OCs. As shown in Fig. 9, iron oxide $\left(\mathrm{Fe}_{2} \mathrm{O}_{3}\right)$, iron aluminum oxide $\left(\mathrm{FeAlO}_{3}\right)$, and alumina $\left(\mathrm{Al}_{2} \mathrm{O}_{3}\right)$ are the major crystalline phases in the SYN-OC, and the two Fecontaining crystalline phases $\left(\mathrm{FeAlO}_{3}\right.$ and $\left.\mathrm{Fe}_{2} \mathrm{O}_{3}\right)$ are active contents for fuel conversion. The direct solidsolid reaction between coal char and the SYN-OC occurs via two reactions, Eq.5 and 6, with the latter reaction as a relatively slow process. So, a stepwise reaction profile was seen as $\mathrm{Fe}_{2} \mathrm{O}_{3}$ and $\mathrm{Fe} \mathrm{AlO}_{3}$ were reduced in sequence, as represented as the blue dashed line of Fig. 8.

$$
\begin{array}{ll}
\mathrm{Fe}_{2} \mathrm{O}_{3}+\mathrm{C} \rightarrow \mathrm{Fe}_{3} \mathrm{O}_{4}(\mathrm{FeO})+\mathrm{CO}_{2}(\mathrm{CO}) & \text { (Fast Reaction) } \\
\mathrm{FeAlO}_{3}+\mathrm{Al}_{2} \mathrm{O}_{3}+\mathrm{C} \rightarrow \mathrm{FeAl}_{2} \mathrm{O}_{4}+\mathrm{CO}_{2} & \text { (Slow Reaction) }
\end{array}
$$

For the RM-OC, XRD patterns show that free $\mathrm{Fe}_{2} \mathrm{O}_{3}$ is active component and other crystalline phases, including calcium titanate $\left(\mathrm{CaTiO}_{3}\right)$, rutile $\left(\mathrm{TiO}_{2}\right)$ and composite salts $\left(\mathrm{CaAl}_{2} \mathrm{Si}_{2} \mathrm{O}_{8}\right.$ and $\left.\mathrm{NaAlSiO}_{4}\right)$ are 
inert support. In our previous research [25], it was shown that the active content (free $\mathrm{Fe}_{2} \mathrm{O}_{3}$ ) of the RM$\mathrm{OC}$ can be completely reduced to metallic iron, and all iron-containing phases involved, i.e. $\mathrm{Fe}_{2} \mathrm{O}_{3}, \mathrm{Fe}_{3} \mathrm{O}_{4}$, $\mathrm{FeO}$ and $\mathrm{Fe}$, do not chemically react with the inert support during reduction. The reaction of the RM-OC with coal char is the reduction of free $\mathrm{Fe}_{2} \mathrm{O}_{3}$ to $\mathrm{Fe}_{3} \mathrm{O}_{4}, \mathrm{FeO}$ or $\mathrm{Fe}$, depending on the OC/fuel ratio. As a result, the weight loss profile exhibits a fast one-step reaction, as shown in the red line of Fig. 8.

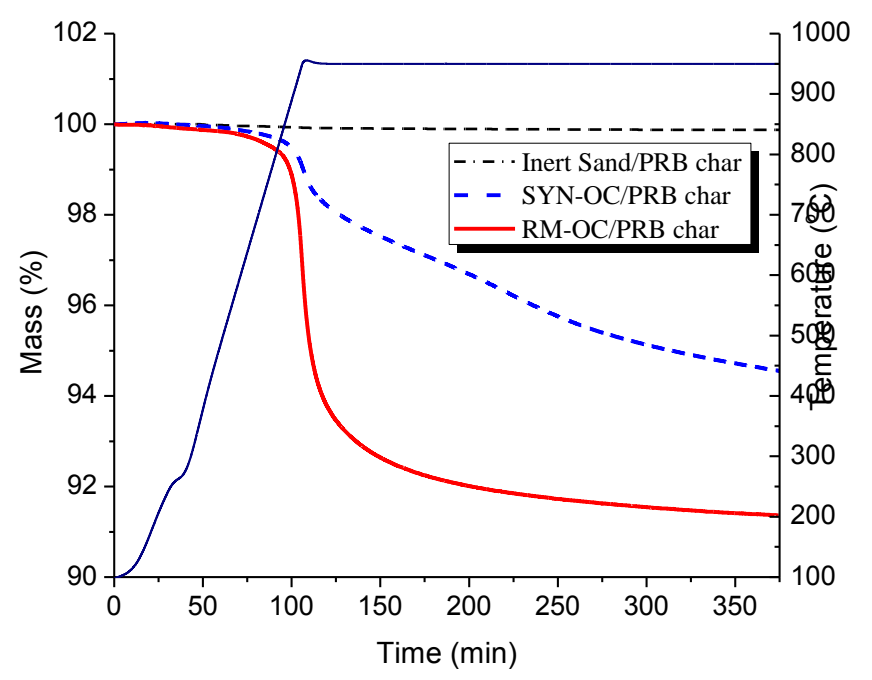

Fig. 8 Weight loss from the static contact solid-solid reaction between PRB char and different solid materials (Heating rate: $10{ }^{\circ} \mathrm{C} / \mathrm{min}$ as $\mathrm{T}>300{ }^{\circ} \mathrm{C}$; terminal temperature: $950{ }^{\circ} \mathrm{C}$; argon flow rate: $200 \mathrm{ml} / \mathrm{min}$ )

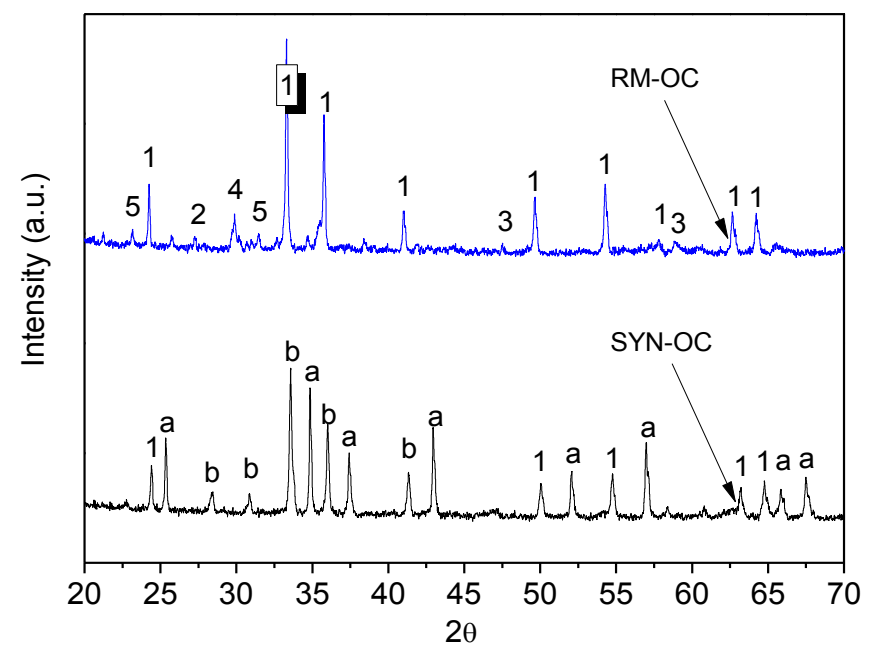

Fig. $9 \mathrm{XRD}$ analysis of iron-based $\mathrm{OCs}\left(\mathrm{a}-\mathrm{Al}_{2} \mathrm{O}_{3} ; \mathrm{b}-\mathrm{Fe} \mathrm{AlO}_{3} ; 1-\mathrm{Fe}_{2} \mathrm{O}_{3} ; 2-\mathrm{TiO}_{2} ; 3-\mathrm{CaTiO}_{3} ; 4-\right.$ $\mathrm{NaAlSiO}_{4} ; 5-\mathrm{CaAl}_{2} \mathrm{Si}_{2} \mathrm{O}_{8}$ )

Fig. 10 (a)-(d) are SEM images of the PRB chars, including the fresh char, and the residual char from the static contact solid-solid reaction. Partially gasified char by $\mathrm{CO}_{2}$ was present for comparison. The partially gasified char was obtained from gasification experiment performed in the TGA at $950{ }^{\circ} \mathrm{C}$ using $50 \% \mathrm{CO}_{2}$ as the gasification agent. The gasification reaction was ended at $\sim 50 \mathrm{wt} \%$ carbon conversion to obtain a partially gasified sample for SEM analysis. The SEM images of the fresh coal char reveal a very dense and smooth carbon surface, and small amount of fine particles distributed across the surface of the 
fresh coal char, as shown in Fig. 10 (a). The surface of the partially gasified coal char (Fig. 10 (b)) underwent edge recession and erosion, both of which are common behaviors in gasification of solid fuel [26]. The residual coal char obtained from the static contact solid-solid reaction is significantly different between the reacted and unreacted areas. As shown in Fig. 10 (c) and (d), the unreacted areas of the residual coal char possess the characteristics of fresh coal char, i.e. dense structure and smooth carbon surface, while the reacted area show shrinkage of the carbon surface and the presence of fine melted particles on the surface. The fine melted particles were semi-quantitatively identified by SEM-EDX, and their elemental spectrum is rich in $\mathrm{Al}, \mathrm{Si}$ and $\mathrm{Na}$, which are intrinsic elements of coal ash. Table 4 summarizes the weight fraction of different elements for fresh carbon surfaces (zone 1 and 2) and the fine melted particles (zone 3 and 4), as shown in Fig. 10 (d).

During the static contact solid-solid reaction, the $\mathrm{CO}_{2}$ gas produced may play a primary role as intermediate gas to continuously gasify the carbon surface of coal char. If so, the carbon surface of the residual coal char should possess characteristics incidental to the partially gasified coal char. However, the SEM images in Fig. 10 do not support this conclusion. The carbon surface of the partially gasified coal char (Fig. 10 (b) left) still exhibits very dense morphology where some Al- and Si- rich fine particle are seen. In the reacted area of the residual coal char from the solid-solid contact reaction, cavities and high porosity are shown on the fresh carbon surface (see Fig. 10 (c) and (d)). During the reaction, some ash-like particles formed on the coal char surface, and show signs of merging to produce larger particles. As a result, the shrinking carbon surface in the reacted area is continuously exposed to the OC for deeper solid-solid reaction.
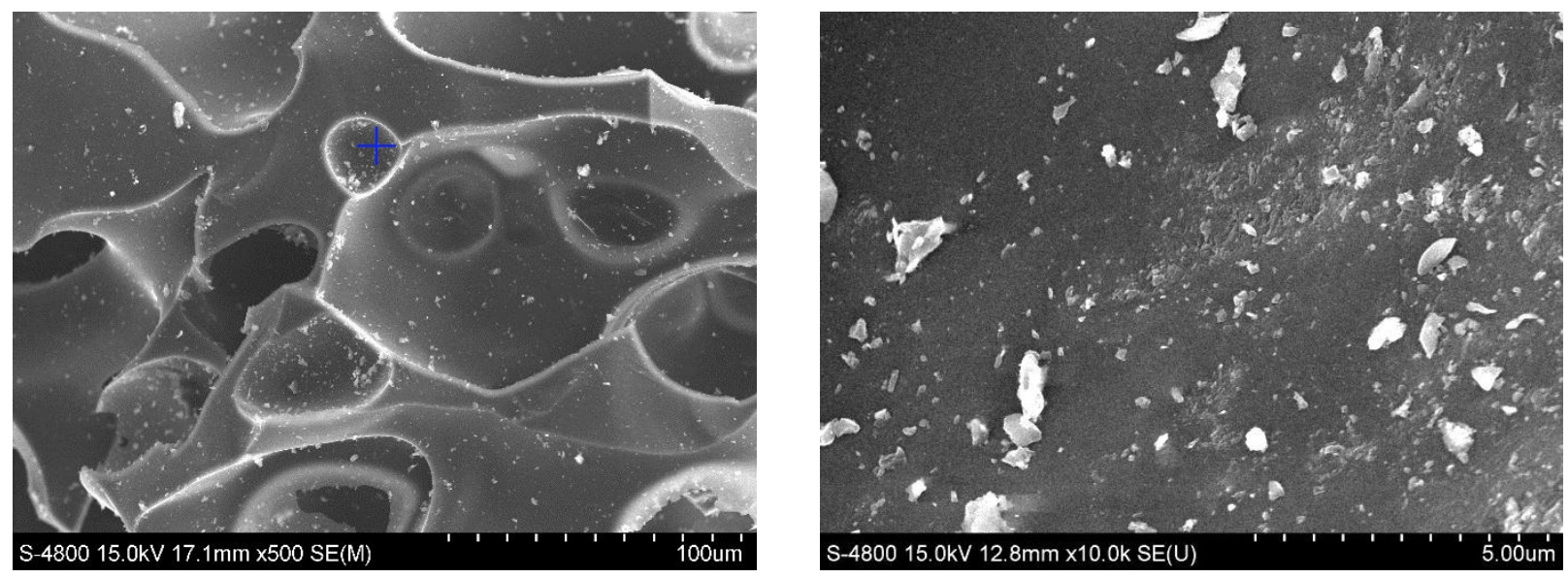

(a) 

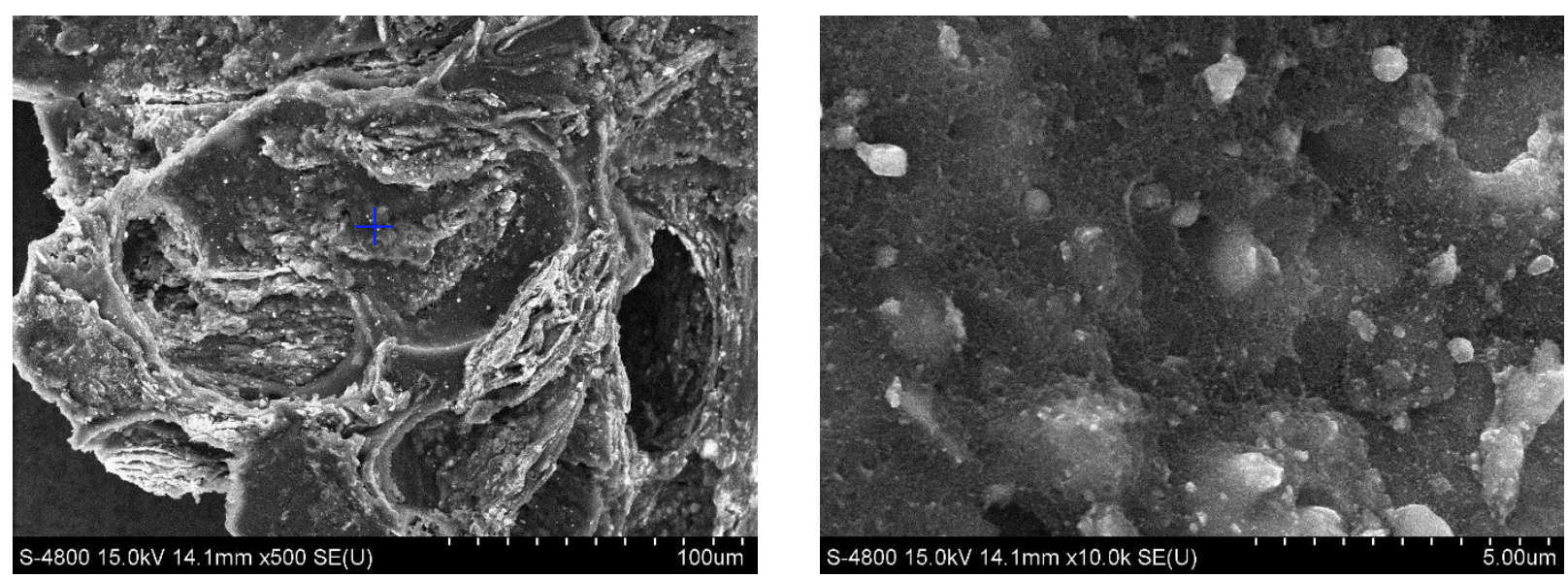

(b)
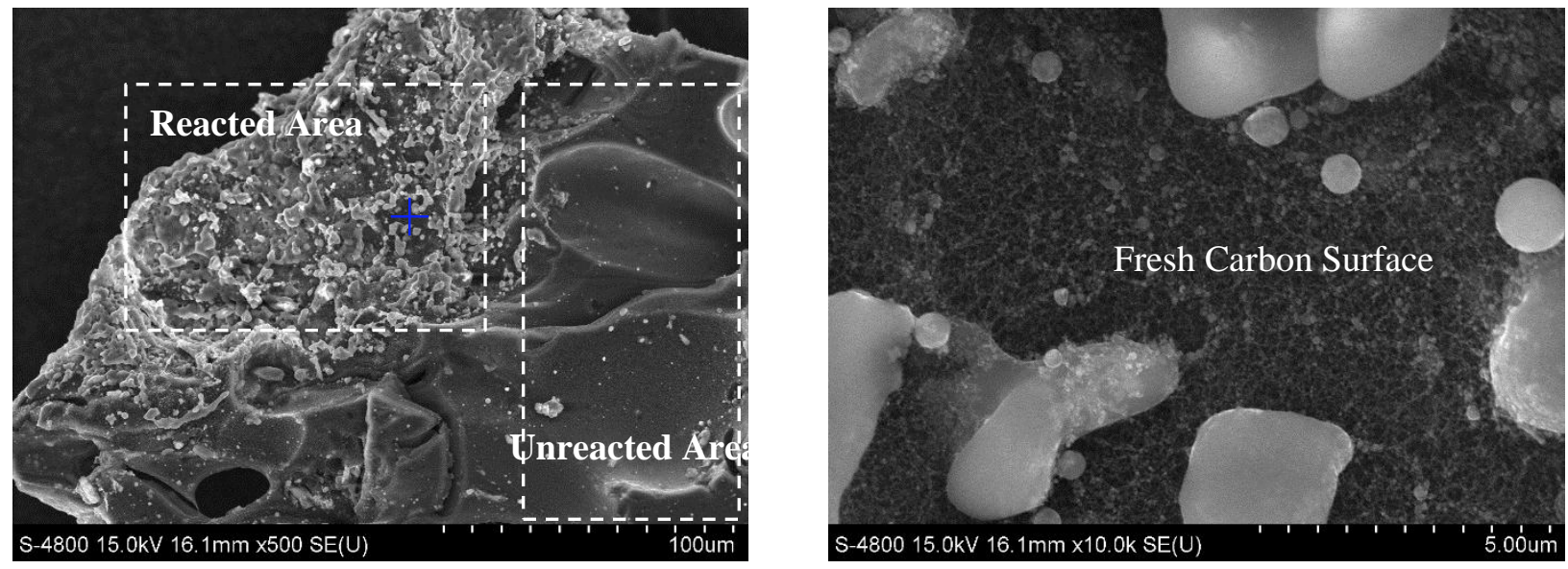

(c)
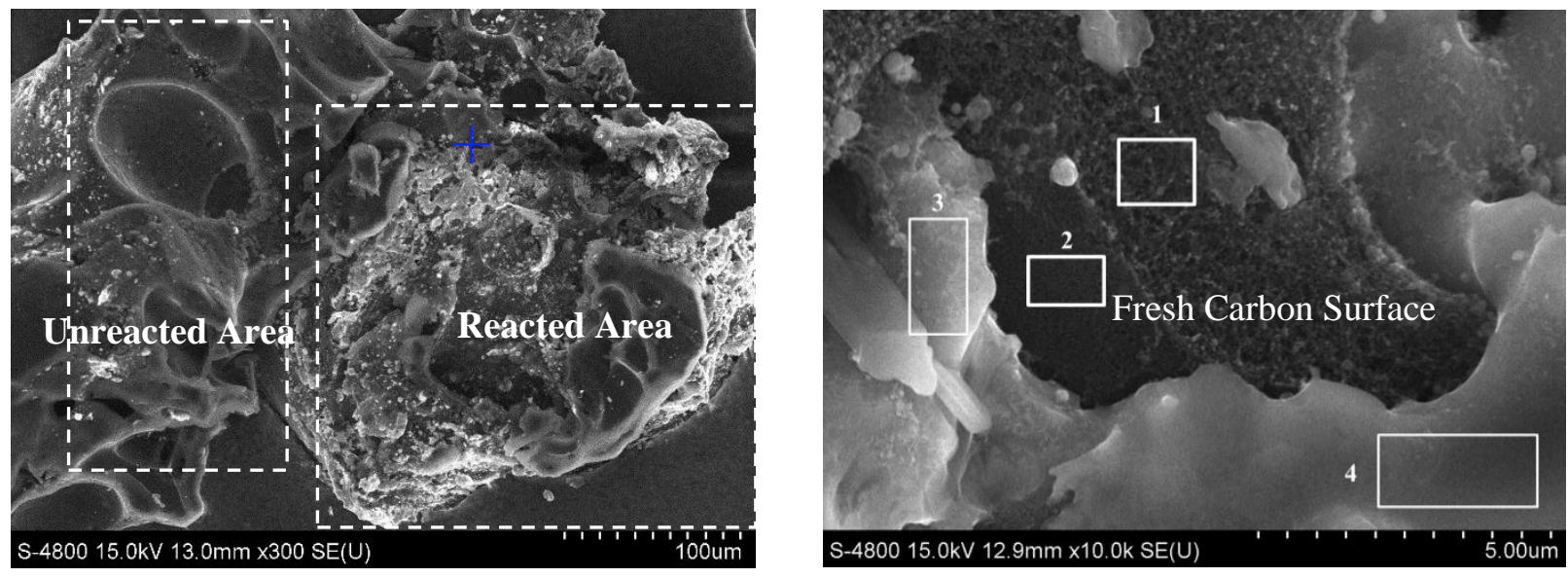

(d)

Fig. 10 SEM images of the fresh and reacted PRB coal chars: (a) Fresh PRB coal char; (b) Residual PRB char after gasification at $950{ }^{\circ} \mathrm{C}$ with $50 \% \mathrm{CO}_{2}$ (sampled at 50\% carbon conversion); (c) PRB char from the static contact solid-solid reaction between char and SYN-OC at $950{ }^{\circ} \mathrm{C}$ (sampled at $32.1 \%$ carbon conversion); (d) PRB char from the static contact solid-solid reaction between char and RM-OC at $950^{\circ} \mathrm{C}$ (sampled at $49.4 \%$ carbon conversion) (note: the crossing "+" in the SEM images of the left column are the locations for higher magnification scanning shown in the right column) 
Table 4 Elemental fraction of zone 1-4 in Figure 10 (d) by SEM-EDX analysis (wt.\%)

\begin{tabular}{lcccc}
\hline Elements & Zone 1 & Zone 2 & Zone 3 & Zone 4 \\
\hline $\mathrm{C}$ & 72.10 & 86.10 & 28.44 & 14.60 \\
$\mathrm{O}$ & 15.69 & - & 47.03 & 53.22 \\
$\mathrm{Na}$ & 2.08 & - & 6.86 & 8.39 \\
$\mathrm{Al}$ & 3.12 & 1.64 & 5.84 & 6.31 \\
$\mathrm{Si}$ & 5.55 & 12.26 & 11.82 & 17.48 \\
\hline
\end{tabular}

\section{Conclusion}

The direct solid-solid reaction between coal char and two iron-based OC particles (the RM-OC and SYNOC) were investigated in the dynamic and static contact regimes. Conclusions are as follows:

(1) The dynamic contact solid-solid reaction between coal char and two iron-based OCs occurs at an appreciable rate without an intermediate gas at the typical operational temperature of CLC $\left(\geq 950^{\circ} \mathrm{C}\right)$. This reaction also leads to high final fuel conversion. The results of the static contact solid-solid reaction show that coal char particles continuously expose fresh carbon surface available to react with the OCs. This allows the direct reaction between coal char and iron-based OC particles to proceed at high fuel conversion.

(2) The operational temperature and use of different OCs significantly affect the reaction kinetics of the solid-solid reaction. The RM-OC exhibited a higher ability of oxidizing coal char than the SYN-OC. Oxidation of coal char was dominated by the type of active content in the OCs that directly react with the solid fuels. When temperature increases from $950{ }^{\circ} \mathrm{C}$ to $1,050{ }^{\circ} \mathrm{C}$, the reaction kinetics of the dynamic contact solid-solid reaction improve by a factor of 7.0 for the RM-OC and 9.2 for the SYNOC.

(3) In steam-gasified CLC, in-situ gasification and the solid-solid reaction appear to be in competition with each other. Higher temperature can significantly promote both of the reactions, but the contribution of the solid-solid reaction to the overall carbon conversion is improved at higher operational temperature. Based on the above reaction mechanism, the use of different solid materials (OCs and solid fuels) and gasification agents $\left(\mathrm{H}_{2} \mathrm{O}, \mathrm{CO}_{2}\right.$, or their mixture) are other major variables that affect the contribution of solid-solid reaction in CLC.

\section{Acknowledgement}

This research was supported by Kentucky Energy and Environment Cabinet Department for Energy (Development and Independence Grant Program), and Energy Research the Carbon Management Research Group consortium (CMRG) at the University of Kentucky, Center for Applied Energy (UKy-CAER), including American Electric Power, Duke Energy, Electric Power Research Institute, L\&GE and KU Service Company, and the Kentucky Department of Energy Development and Independence.

\section{References}

[1] Henrik Leion, Tobias Mattisson, Anders Lyngfelt. The use of petroleum coke as fuel in chemical looping combustion. Fuel 2007; 86 (12-13): 1947-1958. 
[2] Henrik Leion, Tobias Mattisson, Anders Lyngfelt. Solid fuel in chemical looping combustion. Int J Greenhouse Gas Control 2008; 2(2):180-193.

[3] Juan Adanez, Alberto Abad, Francisco Garcia-Labiano, Pilar Gayan, Luis F. de Diego. Progress in chemical-looping combustion and reforming technologies. Progress in Energy and Combustion Science 2012; 38(2): 215-282.

[4] Liang-Shih Fan, Liang Zeng, William Wang and Siwei Luo. Chemical looping processes for $\mathrm{CO}_{2}$ capture and carbonaceous fuel conversion - prospect and opportunity. Energy Environ. Sci. 2012; 5: 7254-7280.

[5] H. Stainton, A. Ginet, K. Surla, A. Hoteit. Experimental investigation of CLC coal combustion with nickel based particles in a fluidized bed. Fuel 2012; 101: 205-214.

[6] Carl Linderholm, Anders Lyngfelt, Ana Cuadrat, Erik Jerndal. Chemical-looping combustion of solid fuels - Operation in a $10 \mathrm{~kW}$ unit with two fuels, above-bed and in-bed fuel feed and two oxygen carriers, manganese ore and ilmenite. Fuel 2012; 102: 808-822.

[7] Rui Xiao, Liangyong Chen, Chiranjib Saha, Shuai Zhang, Sankar Bhattacharya. Pressurized chemical-looping combustion of coal using an iron ore as oxygen carrier in a pilot-scale unit. Int $\mathbf{J}$ Greenhouse Gas Control 2012; 10: 363-373.

[8] Hyung R. Kim, Dawei Wang, Liang Zeng, Samuel Bayham, Andrew Tong, Elena Chung, Mandar V. Kathe, Siwei Luo, Omar McGiveron, Aining Wang, Zhenchao Sun, David Chen, Liang-Shih Fan. Coal direct chemical looping combustion process: Design and operation of a $25-\mathrm{kWth}$ sub-pilot unit. Fuel 2013; 108: 370-384.

[9] Anders Lyngfelt, Chemical-looping combustion of solid fuels - Status of development. Appl Energy 2014; 113: 1869-1873.

[10] Andrew Tong, Samuel Bayham, Mandar V. Kathe, Liang Zeng, Siwei Luo, Liang-Shih Fan. Ironbased syngas chemical looping process and coal-direct chemical looping process development at Ohio State University. Applied Energy 2014; 113: 1836-1845.

[11] John S. Dennis, Christoph R. Müller, Stuart A. Scott. In situ gasification and $\mathrm{CO}_{2}$ separation using chemical looping with a Cu-based oxygen carrier: Perforance with bituminous coals. Fuel 2010; 89: 2353-2364.

[12] Ana Cuadrat, Alberto Abad, Luis F. de Diego, Francisco García-Labiano, Pilar Gayán, Juan Adánez, Prompt considerations on the design of chemical-looping combustion of coal for experimental tests. Fuel 2012; 97:219-232.

[13] Martin Keller, Henrik Leion, Tobias Mattisson, Anders Lyngfelt, Gasification inhibition in chemical-looping combustion with solid fuel. Combust Flame 2011; 158(3): 393-400.

[14] A. Cuadrat, A. Abad, F. Garcia-Labiano, P. Gayan, L.F. de Diego, J. Adanez. Effect of operating conditions in Chemical-Looping Combustion of coal in a $500 \mathrm{~W}_{\text {th }}$ unit. Int $\mathrm{J}$ Greenhouse Gas Control 2012; 6: 153-163.

[15] T. A. Brown, J. S. Dennis, S. A. Scott, J. F. Davidson, and A. N. Hayhurst. Gasification and chemical-looping combustion of a lignite char in a fluidized bed of iron oxide. Energy Fuels 2010; 24, 3034-3048.

[16] Georg L. Schwebel, Henrik Leion, Wolfgang Krumm. Comparison of natural ilmenites as oxygen carriers in chemical-looping combustion and influence of water gas shift reaction on gas composition. Chem. Eng. Res. Des. 2012; 90: 1351-1360. 
[17] Ranjani Siriwardane, Hanjing Tian, Duane Miller, George Richards, Thomas Simonyi, James Poston. Evaluation of reaction mechanism of coal-metal oxide interactions in chemical-looping combustion. Combust Flame 2010; 157 (11): 2198-2208.

[18] John S. Dennis, Stuart A. Scott. In situ gasification of a lignite coal and $\mathrm{CO}_{2}$ separation using chemical looping with a Cu-based oxygen carrier. Fuel 2010; 89(7):1623-1640.

[19] Ranjani Siriwardane, Hanjing Tian, George Richards, Thomas Simonyi, and James Poston. Chemical-looping combustion of coal with metal oxide oxygen carriers. Energy Fuels 2009; 23: 3885-3892.

[20] Aurora Rubel, Kunlei Liu, Jim Neathery, Darrell Taulb. Oxygen carriers for chemical looping combustion of solid fuels. Fuel 2009; 88 (5): 876-884.

[21] Haibo Zhao, Liming Liu, Baowen Wang, Di Xu, Linlin Jiang, and Chuguang Zheng. Sol-GelDerived $\mathrm{NiO} / \mathrm{NiAl}_{2} \mathrm{O}_{4}$ oxygen carriers for chemical-looping combustion by coal char. Energy Fuels 2008; 22: 898-905.

[22] Chern Yean Sim, Tamaryn Brown, Qun Chen, Vida Sharifi, Jim Swithenbank, John Dennis, Stuart Scott. Particle characterization in chemical looping combustion. Chem. Eng. Sci. 2012; 69(1): 211-224.

[23] T. Mendiara, P. Gayán, A. Abad, L.F. de Diego, F. García-Labiano, J. Adánez. Performance of a bauxite waste as oxygen-carrier for chemical-looping combustion using coal as fuel. Fuel Process. Technol. 2013; 109: 57-69.

[24] Golnar Azimi, Henrik Leion, Tobias Mattisson, Anders Lyngfelt. Chemical-Looping with oxygen uncoupling using combined Mn-Fe oxides, testing in batch fluidized bed. Energy Procedia 2011; 4: 370-377.

[25] Liangyong Chen, Yi Zhang, Fang Liu, Kunlei Liu. Development of a cost-effective oxygen carrier from red mud for coal-fueled chemical-looping combustion. Energy Fuels 2015; 29 (1): 305-313.

[26] R.T.K. Baker, J.J. Chludzinski Jr. Catalytic gasification of graphite by chromium and copper in oxygen, steam and hydrogen. Carbon 1981; 19 (2): 75-82. 